\title{
O PROJETO "FILOSOFIA DO NARIZ: INVESTIGANDO ATRAVÉS DO RISO” NO CEGTI RAQUEL DE QUEIROZ
}

The project "Philosophy of the nose: investigating through laughter" at CEGTI Raquel de Queiroz

El proyecto "Filosofía de la nariz: investigando a través de la risa" en CEGTI Raquel

de Queiroz

\section{Paulo Sérgio Gomes Soares ${ }^{*}$, Giovana Miranda Kurovski, Cláudia Rezende Monteiro.}

${ }^{1}$ Curso de Filosofia. Universidade Federal do Tocantins, Tocantins, Brasil

*Correspondência: Coordenação de Filosofia. Av. NS15, Quadra 109N, UFT, Sala 16, CEP 77001-090. Palmas-

Tocantins.e-mailpsoares@uft.edu.br

Artigo recebido em 24/03/2020 aprovado em 09/04/2020 publicado em 18/04/2020.

\section{INTRODUÇÃO}

Esse artigo tem por finalidade relatar e descrever os objetivos alcançados com a intervenção do subprojeto "Filosofia do Nariz: investigando através do riso", implementado no Colégio Estadual Girassol de Tempo Integral Raquel de Queiroz, no município de Palmas - TO, como parte de um projeto maior intitulado "Metodologias alternativas para o Ensino de Filosofia", cujo objetivo foi dinamizar o Ensino de Filosofia a partir da criação e aplicação de uma metodologia alternativa como proposta para ensinar a filosofar para além do textual.

O foco foi a formação de professores. Dentre os subprojetos desenvolvidos na escola, o projeto "Filosofia do Nariz" faz alusão ao nariz de palhaço, chamando a atenção pela forma inusitada com que utilizou o riso como ferramenta para introduzir os temas filosóficos a estudantes que estavam tendo seus primeiros contatos com a disciplina, estudantes da $1^{\text {a }}$ série do Ensino Médio. A preceptora Cláudia Rezende Monteiro afirmou que o principal problema no processo de ensino e aprendizagem no Ensino de Filosofia é a dificuldade dos estudantes em ler, interpretar e escrever textos filosóficos, porém, a residente Giovana Kurovski percebeu que muitos outros problemas permeavam esse processo, como a DOI: http://dx.doi.org/10.20873/uftsupl2020-8708 timidez, a dificuldade em realizar trabalhos em grupo e o estranhamento em relação aos trabalhos manuais ou que envolvem o corpo.

Diante dessa constatação, a residente, que atua profissionalmente como palhaça e como professora de circo, além de desenvolver o seu Trabalho de Conclusão de Curso (TCC) sobre o riso a partir do pensamento do filósofo francês Henri-Louis Bergson (1859 - 1941), resolveu utilizar o riso como ferramenta para despertar o interesse dos estudantes pela Filosofia e minimizar os impactos da apatia.

Para Bergson, o riso possui uma função social e educativa (SANTOS, 2018) e as mesmas técnicas e recursos para provocar o riso, podem também gerar a reflexão e a crítica. A residente ofertou uma oficina de palhaçaria com a intenção de que, através dessa figura irreverente e crítica que o palhaço representa, os estudantes tivessem a possibilidade de explorar o ridículo de forma crítica.

\section{METODOLOGIAS E MATERIAIS}

O projeto foi aplicado com estudantes $1^{a}$ série do Ensino Médio e teve apoio da coordenação, assim como de professores de outras disciplinas, além dos residentes. Foi realizada uma oficina de palhaçaria com nove turmas, envolvendo aproximadamente 250 Revista Desafios - v. 7, n. Supl. RP-UFT, 2020 
estudantes. Os estudantes foram levados para fora da sala de aula e realizaram as atividades sentados ou em pé em um tatame no pátio.

Num primeiro momento, houve uma conversa sobre a arte do palhaço e a história do circo, momento em que os estudantes compartilharam o que sabiam sobre o palhaço e sobre o riso. Depois, começamos a trabalhar de forma mais pontual e teórica, mas expondo exemplos concretos. É importante notar que as pessoas acham que rir é algo natural e nada tem a ver com o aparato cognitivo humano, porém o riso é um tema de estudo filosófico.

Passados os momentos dialógicos, preparamos o caminho para as intervenções com jogos de exercício coletivo. Os estudantes fizeram um aquecimento corporal básico, uma forma também de educar o corpo para as atividades físicas. Primeiro o aquecimento foi feito em formato de roda e individual para que todos se visualizassem para, então, passar para um jogo de aquecimento coletivo para ativar a atenção e soltar o corpo, visando o preparo para jogos que exigem maior criatividade. No jogo inicial, chamado de "Fileira do riso" foram formadas duas fileiras de estudantes, uma de frente para a outra, como dois times, em que a intenção de um time era que todos os componentes do time adversário rissem e o outro time tinha de permanecer sério, depois os times trocaram de objetivo.

Os estudantes precisaram usar a criatividade e inteligência para fazer do próprio corpo um veículo para a ridicularidade a fim de ganhar o jogo, mas desconstruindo o sentido pejorativo de "ridículo", como havia sido conversado no momento dialógico. É necessário romper com a apatia e a timidez, bem como aprender a improvisar. Outro jogo experimentado foi a "entrevista com um Bufão", baseado num jogo intitulado "caricatura" de Boal (1982, p. 120), em que uma pessoa é entrevistada e deve responder naturalmente; cada pergunta feita ao entrevistado é repetida para outros dois jogadores que devem tentar imitar as respostas do entrevistado, procurando nele características e trejeitos passíveis de serem imitados. Neste jogo a intenção é que os estudantes consigam visualizar uma das ferramentas mais utilizadas para provocar o riso: a imitação. Além de exigir que o jogador esteja atento e tenha desenvoltura, este jogo demonstra uma famosa tática de caricaturar e consequentemente expor a críticas, as figuras de poder.

Conforme as turmas iam passando pela oficina os jogos foram sendo adaptados ao envolvimento e as necessidades dos estudantes, visto que enquanto em algumas turmas todos os quarenta participantes se mostravam ativos, em outras havia mais dispersão e apatia, bem como teve estudantes que não demonstraram interesse em participar das atividades. Como se tratava de uma atividade pedagógica, os que não participavam eram encaminhados de volta para a sala para realizar uma atividade escrita compatível com o conteúdo que estava sendo ministrado em aula anterior.

\section{RESULTADOS E DISCUSSÃO}

A fundamentação teórica para a oficina veio dos livros "O elogio da bobagem" (CASTRO, 2005) e "200 exercícios e jogos para ator e não ator com vontade de dizer algo através do teatro" (BOAL, 1982). Do livro de Boal, adaptamos os exercícios de acordo com o contexto escolar. O livro de Castro, por sua vez, fala da função social do palhaço de forma direta e sem o disfarce do palhaço, que além do circo - o seu lugar mais comum -, hoje, é uma figura presente nos hospitais e nas zonas de conflitos armado visando levar alegria onde pode haver pouca esperança. No riso existe uma ética, além do cômico. $\mathrm{O}$ palhaço tem de se preocupar com a maquiagem e com sua imagem de palhaço, pensando na alegria e bem-estar das pessoas. Segundo Castro (2005), o palhaço é uma figura tragicamente cômica cuja função 
é provocar, pelo espanto, o riso. Coincidentemente, o espanto é o primeiro fundamento para se começar a filosofar, pois provoca a consciência, exigindo a reflexão.

Conforme pensa Bergson, quando rimos de uma situação séria ou trágica é porque calamos a sensibilidade e exercemos a inteligência. Para o filósofo, a visão da comicidade é intelectual e desse modo haverá compartilhamento da reflexão sobre o riso com outras inteligências, isto é, com outras pessoas de um determinado grupo social que compreendem determinado objeto, pessoa ou situação como risíveis. (SANTOS, 2018, pp. 145-146).

O espanto provocado pelo palhaço segue um princípio muito parecido com o da Filosofia, embora ao invés da reflexão, gere o riso como condição para a reflexão.

\section{CONCLUSÃO}

Durante um bimestre trabalhamos com projeto Filosofia do nariz na tentativa de apresentar aos estudantes uma abordagem alternativa para introduzir os estudos da Filosofia; por se tratar de turmas da $1^{\text {a }}$ série do Ensino Médio, muitos tinham pouco ou nenhum contato com a disciplina e, portanto, achamos que foi uma maneira descontraída de apresentá-los a todo um conteúdo novo.

As contribuições da Filosofia do Nariz para o Ensino de Filosofia apareceram nas situações de humor e riso que perpassaram o conteúdo curricular de dois bimestres e permitiu a intervenção com uma experiência metodológica alternativa para ensinar a filosofar. Ficou evidente que o riso pode ser um objeto de reflexão filosófica e cumprir uma função social e educativa no cotidiano escolar.

Acreditamos que o ganho foi tanto para os estudantes do Ensino Médio, que experimentaram a Filosofia para além do textual, quanto para a formação de professores, no que tange a percepção da riqueza que envolve o processo de ensino e aprendizagem e a relação entre professor e aluno.

\section{AGRADECIMENTO}

Agradecemos à preceptora. Professora Cláudia Rezende Monteiro, e a toda a equipe gestora do CEGTI Rachel de Queiroz pela receptividade e apoio nas atividades e pela disposição em participar do programa, acreditando nessa parceria entre a escola e a universidade.

Todos os autores declararam não haver qualquer potencial conflito de interesses referente a este artigo.

\section{REFERÊNCIAS}

CASTRO, Alice V. O Elogio da Bobagem: palhaços no Brasil e no mundo. Rio de Janeiro: Ed. Família Bastos, 2005.

COTRIM, G.; FERNANDES, M. Fundamentos de Filosofia. 2. ed. São Paulo: Saraiva, 2013.

BOAL, Augusto. 200 exercícios e jogos para o ator e o não-ator com vontade de dizer algo através do teatro. $4^{\text {a }}$ Edição. Rio de Janeiro: Civilização Brasileira, 1982.

SANTOS, P. D. B. Riso e função social na Filosofia de Bergson. Revista Ideação. $N^{\circ}$. 37, Janeiro/Junho 2018, pp. 144-153. 